SCOTT, J. W. Brain stimulation reinforcement with distributed practice: Effects of electrode intensity. Joumal of Comparative \& Physiological Psy chology, 1967, 63, 175-183. Overnight performance decrement with intracranial reinforcement. Psychological Reports, $1965,16,653-658$.

WASDEN, R. E. Intracranial reinforcement and lished doctoral dissertation, University of Utah, 1966. locus, previous experience, and stimulus

WASDEN, R. E., REID, L. D., \& PORTER, P. B. the overnight performance decrement. Unpub-
WASDEN, R. E., \& REID, L. D. Intracranial stimulation: Performance decrements and a fear-reducing drug. Psychonomic Science, 1968, 12,117-118.

WINER, B. J.Statistical principles in experimental design. New York: McGraw-Hill, 1962.

NOTE

1. This study was supported, in part, by fund from the Faculty Research Committee, Bradley University.

\section{Effects of concurrent exposure to different food and sucrose re- wards in differential conditioning}

JAMES R. ISON and DAVID H. GLASS, University of Rochester, Rochester, N. Y. 14627

In one experiment two control groups were run to either an eight-pellet reward or a one-pellet reward and a discrimination group was run to eight pellets on one stimulus and one pellet on a second stimulus. The discrimination group ran slower to the one-pellet stimulus than did the low-reward control group, indicating the presence of a concurrent depression effect. In the second experiment the same design was used but a high sucrose reward was contrasted with a low sucrose reward. The rate of differentiation was retarded in the sucrose experiment compared to the food pellet experiment and no depression effect was observed, although the functional difference between the sucrose rewards was greater than between the food pellet rewards. These data indicate that the difference between sucrose and food pellet rewards obtained in sequential shift experiments is also obtained in concurrent shift experiments.

Two primary effects are obtained in the usual sequential reward shift experiment in which rats receive a succession of trials with high food reward followed by a succession of trials with a low food reward. Approach behavior, first, rapidly declines, and, second, drops below the level achieved by a nonshift control group which receives low reward throughout. This latter phenomenon defines the sequential "depression effect."

A similar depression effect is obtained in the concurrent reward shift experiment in which rats receive intermixed exposure to the two rewards. In such experiments a high reward is made consequent to one stimulus-response combination and a low with different sucrose rewards, first, should tion (analogous to the slow change in paradigm) and, second, should not provide a concurrent depression effect (analogous to the failure to produce a sequential depression effect). The experiments reported here were performed initially for different purposes. However, they were alike in basic procedural details, and the data are relevant to this point.

\section{SUBJECTS}

Male hooded rats $(\mathrm{N}=70)$, approximately $300 \mathrm{~g}$ in weight were obtained from the Blue Spruce Farms, Altamont, New York.

\section{APPARATUS}

A straight alley ( $83 \times 4 \times 5 \frac{1}{4}$ in.) was painted flat black and covered by frosted Plexiglas. Two side doors, one 12 in. and the other $15^{1 / 2}$ in. from the ends of the alley, served, respectively, as start- and goalbox doors. The runway was placed within a large sound-attenuating hull with a Plexiglas slot in the roof. A 5 -ft fluorescent bulb placed immediately over this slot was illuminated on designated trials by the opening of the start door. The discriminanda were the presence (L) or the absence (D) of this illumination. A $1 / 2$-in. hole in the side of the goalbox permitted access to a drinking tube which contained the appropriate sucrose solution. The drinking tube was controlled by a drinkometer circuit which retracted the tube at the designated lick count. Photocells placed on the start door, and 6 in., 54 in., and $62 \mathrm{in.} \mathrm{down} \mathrm{the} \mathrm{alley,} \mathrm{attached} \mathrm{to}$ Hunter Klockcounters, permitted measurement of start, run, goal, and total times. In the food-reward experiment the aperture in the side of the goalbox was closed and the reward was presented in a glass coaster behind a baffle at the far end of the goalbox. PROCEDURE

One week before training Ss were placed on a $23-\mathrm{h}$ food deprivation schedule (water ad lib) and were handled for $5 \mathrm{~min}$ each day. Within each experiment the rats were randomly assigned to three groups. One lead to relatively slow response differentiaperformance obtained in the sequential
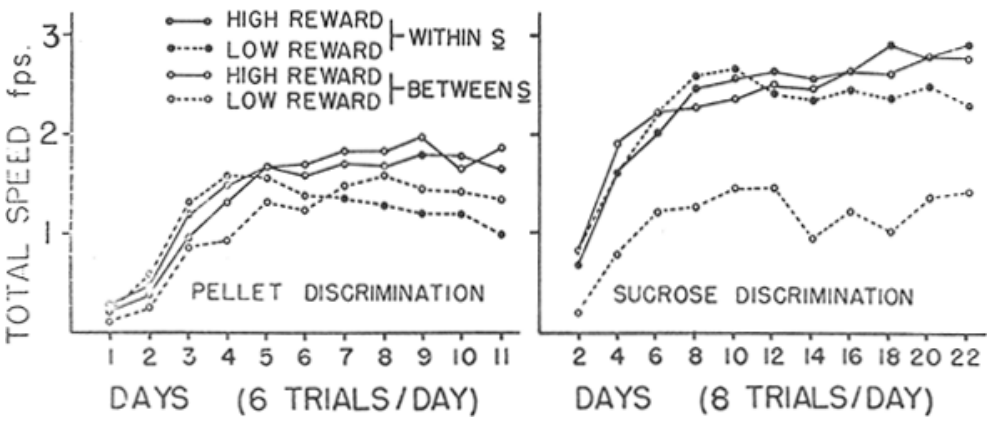

Fig. 1. Mean total response speed for groups receiving only a high reward or a low reward to both stimuli and differential groups receiving the high reward on one stimulus and the low reward on a second stimulus. 
group received a high reward to both discriminanda and a second received a low reward to both; these high- and low-reward control groups provided a between-S comparison of the effect of the two rewards. A third group received a high reward to one of the discriminanda ( $L$ or D) and a low reward to the other ( $D$ or $L$ ) and thus provided a within-S comparison of the effect of the two rewards.

In the food-reward experiment the high reward was eight food pellets (45-mg, Noyes Formula A) and the low reward was one food pellet. Training was given at a rate of three trials to each stimulus on each day and continued for 11 days, by which time all the differential Ss had achieved consistent differential speeds. There were $14 \mathrm{Ss}$ in the high-reward control group, $13 \mathrm{Ss}$ in the low-reward control group, and $27 \mathrm{Ss}$ in the differential group. In the sucrose experiment the high reward was 200 licks of a $20 \%$ sucrose solution and the low reward was 20 licks of a $3 \%$ sucrose solution. Training was given at a rate of four trials to each stimulus on each day and continued for 22 days, by which time all Ss had achieved differential speeds, although this was not consistent for all. There were four $S s$ in the high-reward control group, four $S s$ in the low-reward control group, and eight $S s$ in the differential group.

\section{RESULTS AND DISCUSSION}

Figure 1 depicts mean total response speed for the three groups in both experiments. For the pellet discrimination, speeds to the high and low rewards in the differential group began to diverge after 4 days (24 trials) but in the sucrose discrimination this did not occur until after 10 days ( 80 trials). The critical factor making this difference interesting is that the functional effect of the two kinds of reward differences was apparently greater for the sucrose experiment, as indicated by the greater difference between the speeds of the two control groups in the sucrose experiment compared to the speeds of the control groups in the food-pellet experiment. The control group difference is compatible with the greater nominal difference in the sucrose experiment (about 70 to 1 , combining both number of licks and concentration) compared to the pellet experiment ( 8 to 1$)$.
Further, after the initial separation in the differential group running to the one-pellet reward speeds continued to decline to a level below that of the low-reward control group. This difference, which defines the concurrent depression effect, did not occur in the sucrose experiment.

Analyses of terminal acquisition indicated that both the differential-pellet group (Day $11, \mathrm{~F}=30.00, \mathrm{df}=1,27, \mathrm{p}<.01$ ) and the differential-sucrose group (Days 21 and $22, F=16.81, \mathrm{df}=1,7, \mathrm{p}<.01)$ achieved a reliable differentiation. Further comparisons of the differential group on the low-reward stimulus with the low-reward control group indicated that the terminal depression effect was reliable in the pellet experiment $\left(\chi^{2}=6.65, \mathrm{df}=1, \mathrm{p}<.02\right)$, whereas the difference in the sucrose experiment was in the opposite direction (Fisher's exact test, $\mathrm{p}=.03$ ). The difference between the two control groups was not reliable in the pellet experiment $(p>.10)$, but was reliable in the sucrose experiment $(F=18.19, \mathrm{df}=1,6, p<.01)$.

These data indicate that the different effects of shifts in food-pellet rewards and shifts in concentration and volume of sucrose rewards as obtained in sequential shift experiments similarly occur in the concurrent shift experiment, and suggest, thereby, that the two experimental paradigms engage identical processes. This suggestion is further supported by other demonstrations that variables which reduce the acquisition of differential conditioning also reduce the rate of performance change consequent to a reward decrement in the sequential paradigm. Such demonstrations are available for manipulations of in termittent reward schedules (e.g., Ison, Glass, \& Daly, in press; Pennes \& Ison, 1967) and for injections of amobarbital sodium (e.g., Rosen, Glass, \& Ison, 1967; Ison \& Rosen, 1967).

These latter experiments indicate that the performance changes which occur in each paradigm are produced in part by avoidance responses elicited by the emotional reaction to frustrative nonreward, these avoidance responses being attenuated by partial reward and by the drug. If the conditions of the sucrose experiments also attenuate such avoidance behavior the various effects of changes in sucrose rewards on runway behavior would be readily explicated in one parsimonious theoretical model that can be applied to each of these several manipulations.

The mechanism that may be responsible for this is not readily apparent. One might speculate, however, that the strong consummatory response that generalizes to the low sucrose reward (Ison \& Glass, 1968) is antagonistic to avoidance behavior. Such antagonism may prevent avoidance behavior from working further backwards in the chain of behavior and, thus, prevent disruption of the instrumental approach response.

\section{REFERENCES}

BOWER, G. H. A contrast effect in differential conditioning. Journal of Experimental Psy chol ogy, 1961, 62, 196-199.

HOMZIE, M. J., \& ROSS, L. E. Runway performance following a reduction in the concentration of a liquid reward. Journal of Comparative \& Phy siological Psy chology, 1962. 65, 1029-1033.

ISON, J. R., \& GLASS, D. H. Long term consequences of differential reinforcement magnitudes. Joumal of Comparative \& Phy siological Psychology, 1968, 65, 524-526.

ISON, J. R., GLASS, D. H., \& DALY, H. B. Reward magnitude changes following differential conditioning and partial reinforcement. Journal of Experimental Psychology, in press

ISON, J. R., \& ROSEN, A. J. The effects of amobarbital sodium on differential instrumental conditioning and subsequent extinction. Psychopharmacologia (Berlin), 1967, 10, 417-425.

LUDVIGSON, H. W.. \& GAY, R. A. An investigation of conditions determining contrast effects in differential reward conditioning. Journal of Experimental Psychology, 1967, 75, 37-42.

PENNES, E. S., \& ISON, J. R. Effects of partial reinforcement on discrimination learning and subsequent reversal or extinction. Joumal of Experimental Psychology, 1967, 74, 219-224.

ROSEN, A. J, GLASS, D. H., \& ISON, J. R Amobarbital sodium and instrumental performance changes following reward reduction. Psychonomic Science, 1967, 9, 129-130.

ROSEN, A.J., \& ISON, J. R. Runway performance following changes in sucrose rewards. Psy honomic Science, 1965, 2, 335-336.

\section{NOTE}

1. This research was supported by NSF Research Grant GB 7129 and by NIMH Training Grant MH-10825. 